\title{
Analyzing the Decoupling between Rural-to-Urban Migrants and Urban Land Expansion in Hubei Province, China
}

\author{
Yaolin Liu ${ }^{1,2,3}$, Enxiang Cai ${ }^{1, *} \mathbb{D}$, Ying Jing ${ }^{1}$, Jie Gong ${ }^{1}$ and Zhengyu Wang ${ }^{1}$ \\ 1 School of Resource and Environmental Science, Wuhan University, 129 Luoyu Road, Wuhan 430079, China; \\ yaolin610@163.com (Y.L.); y.crysal@whu.edu.cn (Y.J.); gjie832@163.com (J.G.); \\ wangzhengyu@whu.edu.cn (Z.W.) \\ 2 Key Laboratory of Geographic Information System, Ministry of Education, Wuhan University, \\ 129 Luoyu Road, Wuhan 430079, China \\ 3 Collaborative Innovation Center for Geospatial Information Technology, Wuhan 430079, China \\ * Correspondence: 2015102050044@whu.edu.cn; Tel.: +86-156-2309-5554
}

Received: 1 January 2018; Accepted: 21 January 2018; Published: 29 January 2018

\begin{abstract}
Rapid urbanization in China has caused a large number of rural-to-urban migrants (RUMs) and rapid urban land expansion (ULE). Understanding the relationship between RUMs and ULE has important implications for urban sustainable development. This study explored the spatial patterns of RUMs and ULE in Hubei Province from 2009 to 2014, and analyzed the relationship between the two using a decoupling model. The results show that: (1) a large proportion of the rural population migrated to urban areas in Hubei Province from 2009 to 2014, and the distribution of RUMs was uneven: developed areas attracted more RUMs than undeveloped regions; (2) the urban land in Hubei Province increased rapidly from 2009 to 2014, and the urban land use in Hubei Province was extensive and inefficient; (3) the decoupling types between RUMs and ULE in Hubei Province were dominated by expansive negative and weak decoupling; (4) according to the changes in per capita urban land area and decoupling types, the coordination relationship between RUMs and ULE in Hubei Province was divided into eight types, and while the relationship between RUMs and ULE in most areas were coordinated and beneficial to urban land intensive use, the rest were uncoordinated. Finally, reasonable implications for urban sustainable development and new land use policy were put forward.
\end{abstract}

Keywords: rural-to-urban migrants; urban land expansion; decoupling; coordination relationship; Hubei Province

\section{Introduction}

Since the initiation of the "reform and opening-up" policy in 1978, China has made great achievements in social and economic development, and undergone unprecedented urbanization [1]. This urbanization has caused the phenomena of a monumental flow of rural-to-urban migration and dramatic spatial expansion in the scale of urban land in China [2,3]. Urbanization has made a significant impact on the man-land relationship between urban and rural areas in China while contributing to sustained social and economic development. The study of the change of the man-land relationship triggered by the rapid urbanization in China has emerged as a hot topic worldwide [4].

The phenomena of urban growth and population growth occur in all countries of the world, and particularly in those with industrial economies [5,6]. According to a report by the United Nations (2010), more than $50 \%$ of the world's population nowadays lives in urban areas, and the urbanization rate will increase to $60 \%$ by 2030 [7]. The continuous migration from rural to urban areas increases the proportion of people living in towns and cities [8]. This urbanization has caused 
$80 \%$ percent of the population to live in urban settlement areas in many countries across Europe [9], America, and Oceania [10]. The presence of rapid urban population growth has created difficulties for governments in relation to urban management, because it has also created a lot social and natural problems, such the depletion of land resources, man-land relationship tensions, public resource shortages, and traffic congestion [11,12]. As a result, authorities need to provide more land to increase public facilities and meet residents' social welfare needs. The urban expansion induced by population growth has been widespread over the past decades in the United States [13], Europe [9,14], China [15], and India [16]. However, urban expansion without guiding principles is inadvisable. In other words, reasonable and effective land expansion is a crucial part of urban management, due to the presence of a floating population and residential density [17].

As an outcome of economic growth, urban land expansion (ULE) in China is proceeding at a high speed [1]. Some scholars even argued that ULE in China has outpaced urban population growth and caused inefficient urban land use $[18,19]$. Some of problems associated with rapid ULE include climate change [20,21], cropland loss [22], wetland destruction [23], and air and water pollution [24]. These problems lead to a reduced quality of life both in urban and rural societies [25]. On the one hand, ULE has inevitably caused a series of resource and environmental problems and cropland protection issues throughout China [26]. On the other hand, since the Chinese economy relies firmly on land inputs, local governments have quickly expanded urban land [27]. The Chinese government is trapped in the dilemma of controlling the expansion of UCL and guaranteeing the demand of economic development for urban land. In this context, studying the spatial and temporal characteristics of ULE and putting forward a reasonable plan for urban land use can be particularly important for urban sustainable development.

In the process of the rapid economic growth of the past three decades, China has been experiencing rapid urbanization, as well as the largest flow of rural-to-urban migration in the history of word. While only $18 \%$ of the population lived in urban China in 1978, over 50\% reside in cities today [28]. As an important driving force for urbanization and economic development, rural-to-urban migrants (RUMs) have an inextricable link with China's ongoing urbanization process and its profound social ramifications [3]. There is a wealth of literature on China's RUMs and urbanization. There are many studies that examine the discrimination against rural migrants and their inferior social and labor market positions $[29,30]$. Studies have also suggested negative health well-being consequences from rural-to-urban migration for migrants themselves [31], and to the elderly and children left behind in the rural areas [32,33]. The decision and determinants of rural-to-urban migration also concern many scholars [34,35]. Although previous research has generated an impressive body of work, most of the existing studies explore the social issues that are caused by RUMs. Despite RUMs and ULE being important characteristics of urbanization, empirical analyses of the relationship between the two have been limited.

Based on the above research streams, there is a gap in the literature in studying the decoupling relationship between RUMs and ULE. In order to contribute by filling this literature gap, we take Hubei Province as a case study for quantitatively analyzing the decoupling characteristics of RUMs and ULE. Hubei Province in Central China was used as a case study due to its rapid urbanization and the obvious differences between its east and west regions. In the present study, we aimed to: (1) explore the changes in RUMs and ULE in Hubei Province from 2009 to 2014; (2) examine the types of decoupling between RUMs and ULE; and (3) classify the coordinating relationships, and bring forward targeted suggestions for sustainable urban land use.

\section{Methodology}

\subsection{Rural-to-Urban Migrant (RUM) Estimation Model}

Urban population growth in China mainly comes from three areas: natural, migration, and administrative division change growths [36]. The acceleration of urbanization has made migration 
growth gradually become the main reason for urban population growth [37]. The Chinese population has obvious rural-to-urban migration direction characteristics [38]. We argue that the migration population that caused urban population growth is RUMs, and the migration from urban-to-urban was not considered. The administrative divisions at the county level in Hubei Province were not adjusted from 2009 to 2014; therefore, natural and migration growth were the causes of urban population growth. After referring to relevant research and estimation methods [3], the number of RUMs can be estimated by subtracting the population of natural growth from the total population growth during the study period. The specific calculation is shown in Equation (1):

$$
P_{m}=P_{n}-P_{0}-P_{0} \times\left[\prod_{1}^{n}\left(1+r_{i}\right)-1\right]
$$

where $P_{m}$ is the number of RUMs, $n$ is the number of years, $P_{n}$ is the urban population in the current year, $P_{0}$ is the urban population in the base year, and $r_{i}$ is the natural growth rate of the population in year $i$.

\subsection{Decoupling Model}

A particularly useful way to examine the relationship between RUMs and ULE is by viewing it within the framework of decoupling. There are many definitions and arguments of "decoupling", but the concept of decoupling originated in physics, and is a means of reducing or eliminating the coupling of one circuit or part from another. Carter (1966) first introduced this to the economic and environmental fields to describe the decoupling relationship between energy consumption and economic growth [39]. Subsequently, the decoupling theory became popular and widely used in the fields of energy consumption, economic, environment, etc. The Organization for Economic Co-operation and Development (OECD) (2002) initially set up the decoupling index to track environmental quality changes in its 30-member state, and formed the carbon decoupling theory [40]. Tapio (2005) improved the decoupling index to analyze the relationship between gross domestic product (GDP), traffic volumes, and $\mathrm{CO}_{2}$ emissions in the European Union (EU) [41]. Additionally, he defined eight categories of decoupling status. Romano and Zullo (2014) used a similar method to examine the relationship between land urbanization and population growth in Italy [42]. Decoupling analysis has widely applied for studying the relationship between two different systems $[43,44]$.

In this study, the decoupling analysis was used to assess the relationship between RUMs and ULE. To ascertain the status of decoupling, we used Tapio's model [41], which can be an expression in terms of elasticity values, as shown in Equations (2)-(4). The decoupling elasticity value $\alpha$ calculated by Equation (2) is the basis for determining the type of decoupling between RUMs and ULE. Equations (3) and (4) are used to measure the speed of rural-to-urban migration and urban land expansion, respectively:

$$
\begin{gathered}
\alpha=I R / E R \\
I R=P_{m} / P_{0} \\
E R=\frac{U A_{n}-U A_{0}}{U A_{0}}
\end{gathered}
$$

where $\alpha$ is the decoupling elasticity value of RUMs and ULE, IR is the immigration rate of RUMs, $E R$ is the expansion rate of urban land, $U A_{n}$ is the area of ULE in the current year, and $U A_{0}$ is the area of ULE in the base year.

According to the elasticity value in Equation (2), the study defines eight categories of different decoupling states (Table 1). The IR (immigration rate of RUMs) and ER (expansion rate of urban land) (see Equations (3) and (4) above) can be coupled, decoupled, or negatively decoupled. In order not to over-interpret slight changes as significant, a $\pm 20 \%$ variation of the elasticity values around 1.0 are 
still regarded as coupling here. Thus, coupling is defined as elasticity values of 0.8-1.2. On the other hand, the growth of the variables can be positive or negative per se, expressed as expansive coupling and recessive coupling. In Table 1, the eight decoupling have different meanings. For example, strong decoupling is indicated by a negative change rate of the RUMs indicator and a positive change rate of ULE growth. Other decoupling states can be explained similarly.

Table 1. Decoupling states between rural-to-urban migrants (RUMs) and urban land expansion (ULE).

\begin{tabular}{cccccc}
\hline Decoupling & \multicolumn{3}{c}{ Negative Decoupling } & Coupling \\
\hline Strong & $I R<0, E R>0$ & Expansive negative & $I R>0, E R>0$ \\
& $\alpha<0$ & & Expansion & $\begin{array}{c}I R>0, E R>0 \\
0.8<\alpha<1.2\end{array}$ \\
\hline \multirow{2}{*}{ Weak } & $I R>0, E R>0$ & Weak negative & $\begin{array}{c}I R<0, E R<0 \\
0<\alpha<0.8\end{array}$ & Recession & $\begin{array}{c}I R<0, E R<0 \\
0<8<\alpha<1.2\end{array}$ \\
\hline \multirow{2}{*}{ Recession } & $I R<0, E R<0$ & Strong negative & $I R>0, E R<0$ & \\
& $\alpha>1.2$ & & & \\
\hline
\end{tabular}

\section{Study Area and Data Source}

\subsection{Study Area}

Hubei Province is in the middle reaches of the Yangtze River in Central China $\left(29^{\circ} 05^{\prime}-33^{\circ} 20^{\prime} \mathrm{N}\right.$ and $108^{\circ} 21^{\prime}-116^{\circ} 07^{\prime} \mathrm{E}$ ), and has a varying topography that includes mountains, hills, basins, and plains, covering an area of $185,900 \mathrm{~km}^{2}$. The topography of Hubei Province is west high, east low. The west is a high-elevation mountain area, and the northeast and southeast are hilly areas. The middle part is the flat Jianghan Plain (alluvial area of the Yangtze River and the Hanjiang River), which is an important food production area (Figure 1).

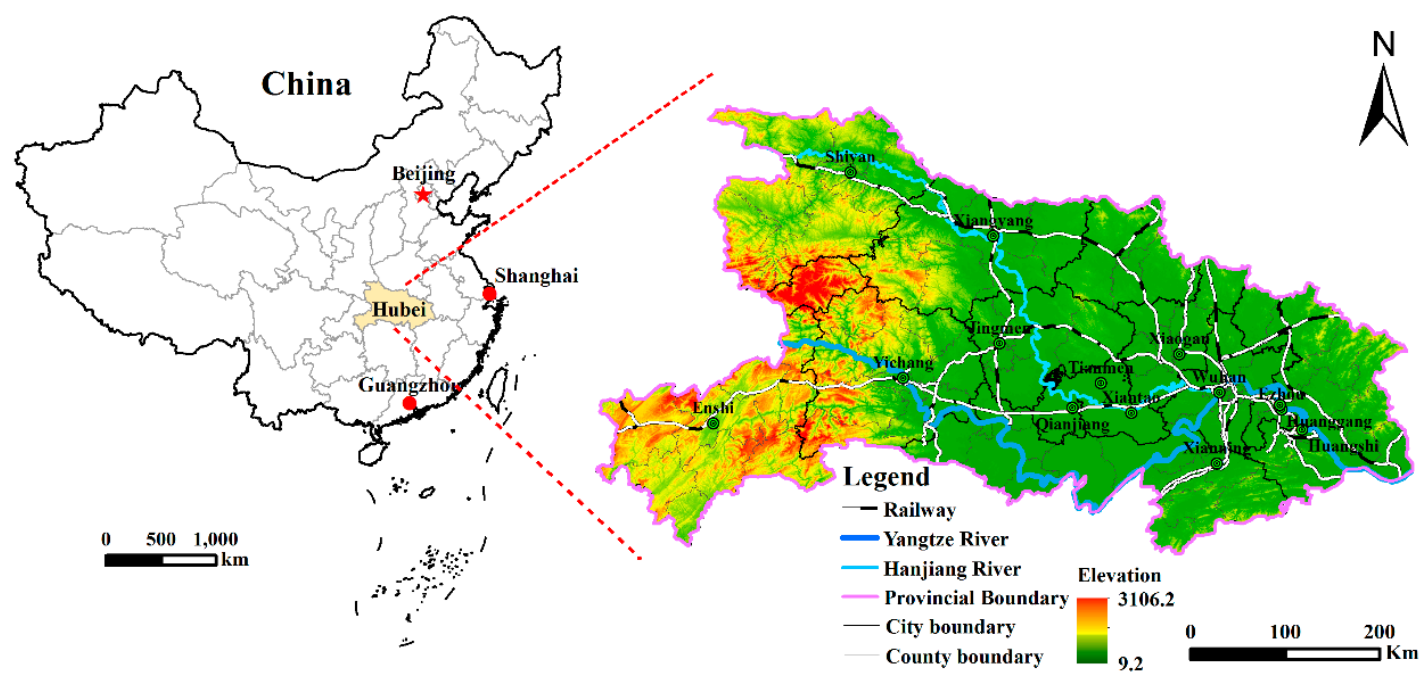

Figure 1. Location, administrative divisions, and elevation of Hubei Province.

As the fulcrum province of the "Rise of Central China" national strategy and the Yangtze River Economic Belt, Hubei Province has been accelerating its development process, increasing its GDP from 21.98 to 2737.92 billion yuan, and increasing its urbanization rate (proportion of urban population) from $17.2 \%$ to 55.67\% between 1981 and 2014 [45]. As shown in Figure 2, the development of the economy and urbanization of Hubei Province is consistent with that of China, thereby making this province a typical subject for studying China. From 2009 to 2014, the area of urban land in Hubei Province increased from $11,638 \mathrm{~km}^{2}$ to $12,814 \mathrm{~km}^{2}$, the urban population showed a marked increase, and the 
rural population decreased. Hubei Province is in an accelerated development stage of urbanization [46], the rapid urbanization will lead to continued urban expansion and rural-to-urban migration.
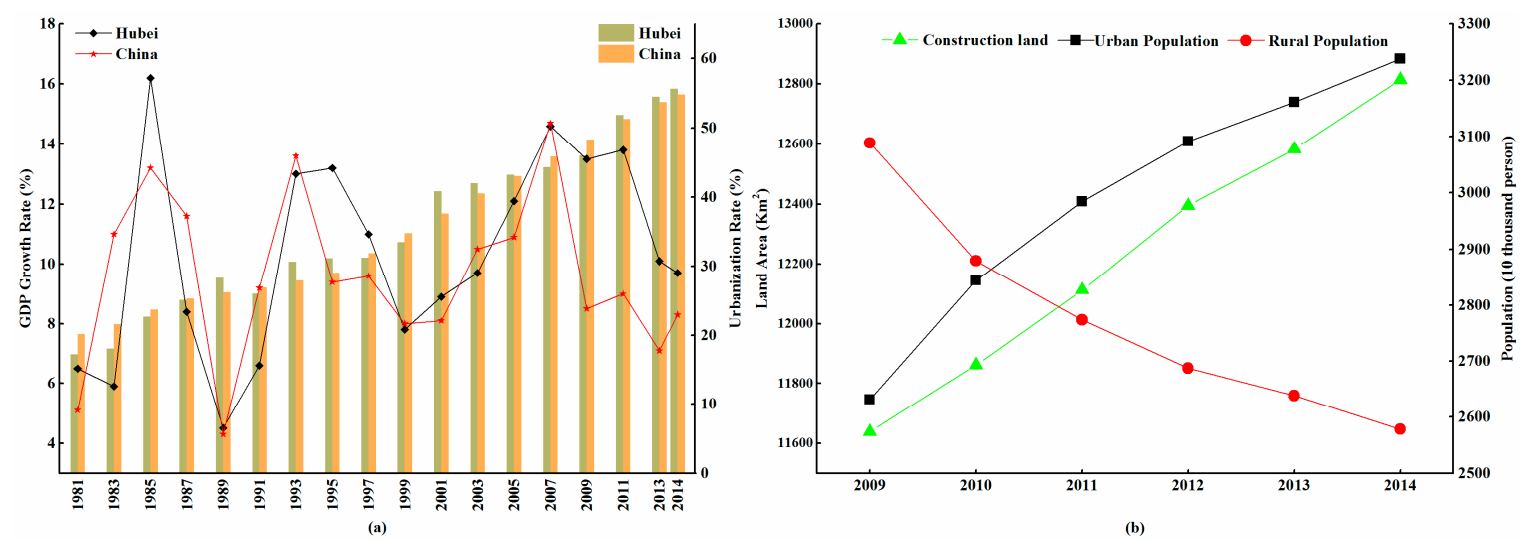

Figure 2. Changes in (a) GDP rate and urbanization rate and (b) construction land area and the urban-rural population in Hubei Province.

\subsection{Data Source}

The land use data were obtained from land use and cover vector data at a 1:10,000 scale, and derived from the Second National Land Survey (SNLS) in 2009 and the Annual Land Use Change Survey (ALUCS) in 2014. The SNLS, which was conducted from 2007 to 2009, is a national systematic territory survey project organized by China's State Council. The land use data obtained from the SNLS has a wide coverage and high accuracy on the basis of advanced technologies and management techniques. Meanwhile, the ALUCS has been running since 2010 to annually update the SNLS data and collect yearly land use information. Thenceforth, a series of official, accurate, and comprehensive digital data reflecting the situation of land use in China was formed. The data of SNLS and ALUCS stand out as the most comprehensive and coherent quantifications of China's land with legal effects [47]. The land use classification used by SNLS and ALUCS is the Current Land Use Condition Classification (GB/T21010-2007) scheme, which comprises nine one-digit categories and 23 two-digit categories [48]. The urban land in this paper refers to urban residential land, including urban land and town land.

The socioeconomic data about GDP and population were from the statistical yearbook of Hubei Province (2010 and 2015) and various cities in the region (2010 and 2015) [45,49]. China's statistics department did not publish data on the natural growth rate of the urban population, which was therefore replaced by the natural growth rate of the total population in this study.

\section{Results}

\subsection{Patterns of RUMs}

The urban population in Hubei Province increased from 26.31 million to 32.38 million from 2009 to 2014, which reflects an increase of 6.07 million [45], of which 5.44 million were RUMs. The immigration rate of total RUMs in Hubei Province was $20.69 \%$. The average number of RUMs per county was 62,571 . Four areas in the upper reaches of the Hanjiang River, namely, Xiangyang city, Laohekou, Zaoyang, and Danjiangkou, had a negative number of RUMs between 2009 and 2014, which means that the immigrants from rural areas were less than the reduction of the urban population. The upper reaches of the Hanjiang River are the source of water supply of the middle route of the south-to-north Water Diversion Project; as a result of the eco-immigration policy, a large number of local residents migrated to other counties (an ecological protection policy in China is to migrate the residents who live in an ecological reserve to suitable habitats). 
The spatial distribution of RUMs presented spatial differentiation. As shown in Figure 3, the number of RUMs in the eastern region was obviously higher than that in the west. The RUMs were mainly distributed in economically developed regions, such as the provincial capital Wuhan and the areas in the Jianghan plain. The immigration rate of RUMs showed an opposite spatial pattern to the RUM number. The immigration rate in most parts of the west was higher than that in the east. This is mainly due to the lower original urban population proportion in these western regions, which enables them to experience faster urbanization development.

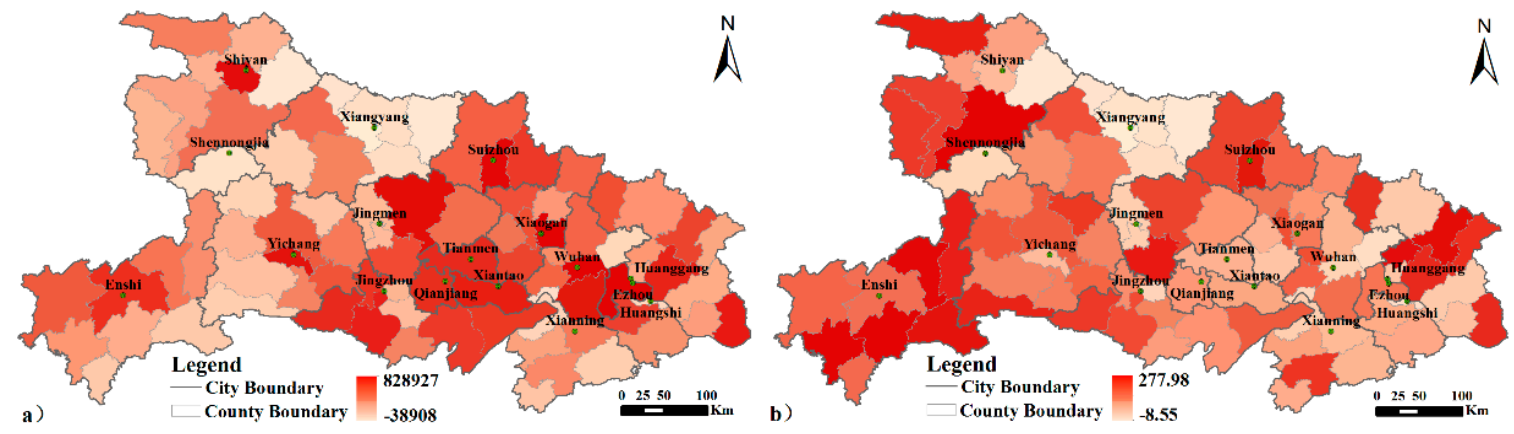

Figure 3. Spatial patterns of RUMs in Hubei Province. (a) RUM number (unit: persons); (b) immigration rate (unit: \%).

\subsection{Changes in Urban Land Area}

The urban land in Hubei Province expanded rapidly from 2009 to 2014. The total area of urban land increased by $1126.19 \mathrm{~km}^{2}$, with an increased rate of $40.64 \%$. In the county-level units, the urban land areas in all of the regions of Hubei Province have increased. Generally, economically developed regions showed a larger increased urban land area. The areas with a large increased urban land area were mainly in Wuhan and its vicinity. The urban areas of certain cities (e.g., Yichang, Xiangyang, Shiyan, Enshi, Xiangyang, and Xiaogan) also had a large increase (Figure 4). In contrast, the increased urban area of the economically backward regions in the west was obviously lower than that of other areas. The spatial distribution of the increased rate of urban land area was scattered. Unlike the increased urban land area, the increased rate of urban land area in the most developed areas, such as the counties in Wuhan, was not the highest. Some regions in the middle and western parts of Hubei Province that are experiencing rapid economic development showed a higher increased rate of urban land area.

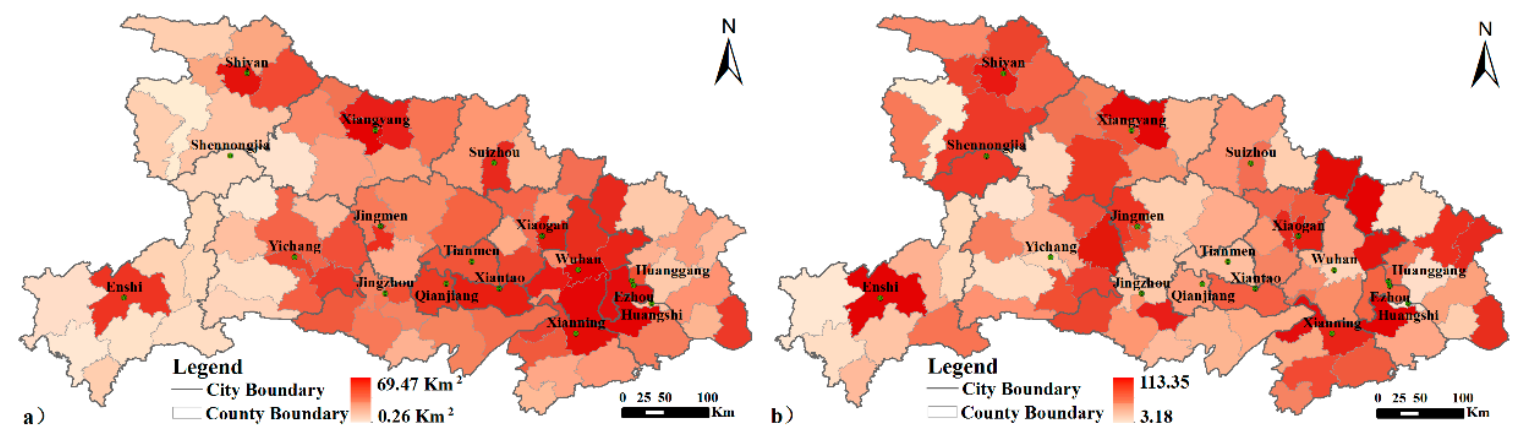

Figure 4. Spatial patterns of ULE in Hubei Province. (a) Increased area; (b) increased rate.

Per capita urban land area (PCULA) is an important indicator of urban land use intensity [50], and is considered the national urban land use guideline for promoting the "construction of a resource-efficient society" in China [51]. According to the Code for the Classification of Urban Construction Land Use and Planning Standards of Development Land issued by the Ministry of 
Housing and Urban-Rural Development in 2012 [52], the national standard of PCULA in Hubei Province is $110 \mathrm{~m}^{2}$. If PCULA exceeds the national standard, urban land use is deemed extensive and unsustainable.

PCULA in Hubei Province increased from $105.31 \mathrm{~m}^{2}$ in 2009 to $120 \mathrm{~m}^{2}$ in 2014 . The urban land use in Hubei Province was extensive and inefficient. Figure 5 shows that PUULA decreased in most areas of Hubei Province (62 of 87 units) from 2009 to 2014, but nearly 2/3 of the areas (57 of 87 units) still exceeded the national standard in 2014. In particular, in some areas of the economically developed central and eastern regions, the urban land use was extensive, and the intensity decreased with time. These areas feature a flat terrain and favorable nature conditions for land development. However, the speed of urban expansion was far greater than the population growth, which leads to extensive urban land use. In the future, reasonable land management policies should be adopted to maintain the coordinated growth of urban land and population.

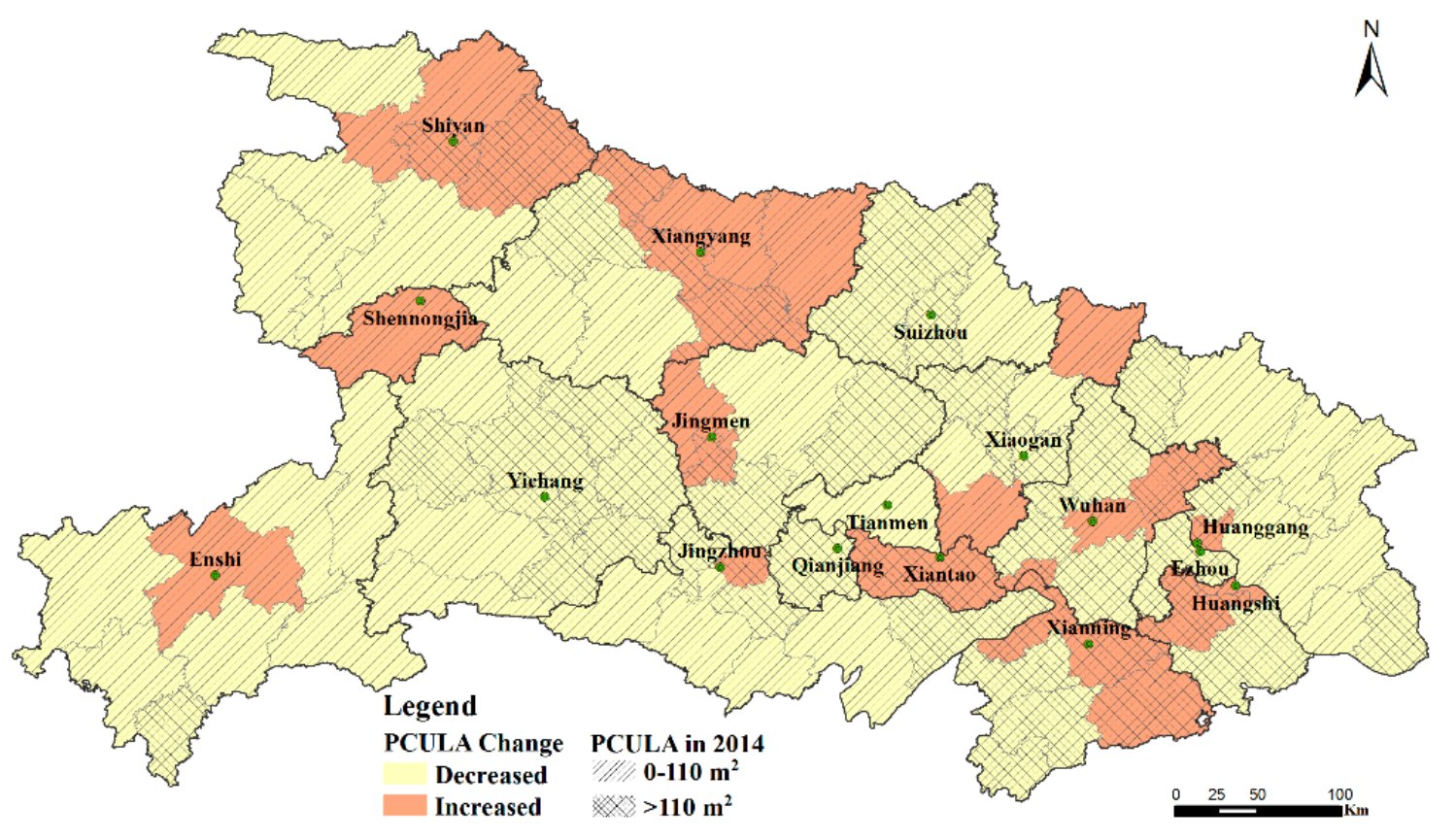

Figure 5. Per capita urban land area (PCULA) in 2014 and its changes from 2009 to 2014.

\subsection{Decoupling between RUMs and ULE}

From 2009 to 2014, the immigration rate in Hubei Province was 20.69\%, and the UCL growth rate was $40.64 \%$. The decoupling was weak decoupling with an elasticity value of 0.51 , which indicates that the expansion of urban land was faster than the growth of RUMs, and will lead to inefficient and extensive urban land use. As shown in Table 2, the proportion of counties in Hubei Province belonging to each type during this period is as follows: expansion coupling ( 11 of 87 units), expansive negative decoupling (56 of 87 units), weak decoupling (16 of 87 units), and strong decoupling (four of 87 units). At the county level, the speed of RUMs growth in most areas was faster than that of ULE or vice versa, while the speed of RUMs growth was consistent with that of ULE only in a few areas. Therefore, it can be concluded that the relationship of the RUMs and ULE in Hubei Province did not reach a coordinative situation. 
Table 2. Decoupling between RUMs and UCL expansion in Hubei Province.

\begin{tabular}{ccc}
\hline Decoupling Types & Number & Sample Areas \\
\hline Expansive Coupling & 11 & Wuhan city, Yunyang, Dawu, Yingcheng \\
\hline $\begin{array}{c}\text { Expansive Negative } \\
\text { Decoupling }\end{array}$ & 56 & $\begin{array}{c}\text { Dongxihu, Caidian, Jiangxia, Huangpi, Yangxin, } \\
\text { Yunxi, Zhushan, Fangxian }\end{array}$ \\
\hline Weak Decoupling & 16 & Hannan, Xinzhou, Daye, Yicheng, Xiangzhou \\
\hline Strong Decoupling & 4 & Danjiangkou, Xiangyang city, Laohekou, Zaoyang \\
\hline
\end{tabular}

The eastern and western regions of Hubei Province showed different decoupling patterns (Figure 6). Due to the mountainous areas in the western part of Hubei Province, the economic development has lagged behind, and the urbanization level was low. In recent years, the local government has vigorously promoted economic development, and a large proportion of the rural population has consequently migrated to cities; as a result, the urban population growth was faster than urban land growth in most parts of western Hubei. Therefore, the western part of Hubei Province was dominated by expansive negative decoupling. In the eastern part of Hubei Province, the developed economy led to a strong demand for urban land and superior land development conditions. As a result, urban expansion has been fast, and the decoupling types of many counties in the east were weak decoupling or expansive coupling. As a result of eco-environmental policies, the rural population migrated to other counties; four counties in the upper reaches of the Hanjiang River had a strong decoupling type.

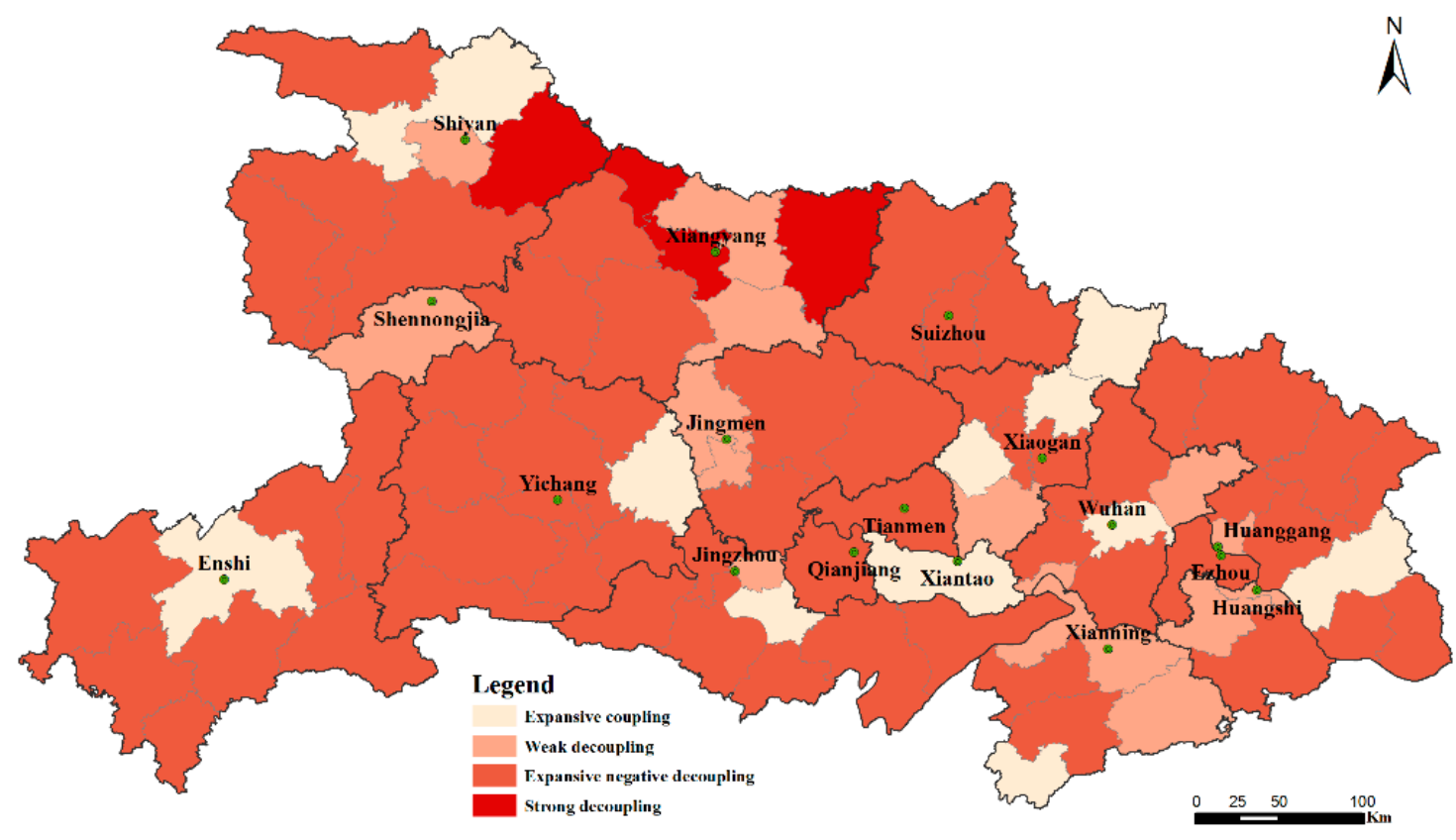

Figure 6. Decoupling patterns in Hubei Province from 2009 to 2014.

\subsection{Coordination Relationship between RUMs and UCL}

PCULA can be used to reflect the coordination relationship between RUMs and ULE, and provide enhanced guidance for urban land use. To make the decoupling analysis of RUMs and ULE more targeted for land use decision-making, we classified the coordination relationship between RUMs and ULE in Hubei Province into eight categories on the basis of the results of the decoupling analysis and the change of PCULA (Table 3 and Figure 7). The PCULA of types I, II, III, and IV was lower than the national standard in 2014; their urban land use was intensive. Meanwhile, the PCULA of types V, 
VI, VII, and VIII were higher than the national standard in 2014; their urban land use was extensive. According to the coordination relationship between RUMs and ULE, the corresponding suggestions for each were then put forward.

Coordinated status: the urban land use was efficient or became increasingly intensive due to the changes in RUMs and ULE. Type I, II, V, and VI belong to this status. The RUMs growth kept pace with or exceeded the ULE growth, which led to an increasing urban land use intensity; the urban land use in this status was sustainable. The PCULA of type I and II was lower than the national standard in 2014; therefore, the approval of the quota for new urban land should be relaxed, and the supply of urban land should be given priority in the future. Meanwhile, the PCULA of type V and VI was higher than the national standard in 2014; therefore, the approval of the quota for urban land use should be restricted, and the supply of urban land should maintain the status quo to increase urban land use intensity.

Uncoordinated status: the urban land use was inefficient or became increasingly extensive due to the changes of RUMs and ULE. Type III, IV, VII, and VIII belong to this status. The ULE growth was faster than the RUMs growth in order to reduce land use intensity, which makes the urban land use in this status unsustainable. Although the PCULA of type III and IV was lower than the national standard in 2014, the urban land is developing in the direction of extensive use; therefore, the approval of the quota for new urban land should be reduced to ease the rapid urban expansion. The PCULA of type VII and VIII was higher than the national standard in 2014, and there is a tendency for it to continue to increase; therefore, the approval of the quota for new construction land should be strictly restricted, and the supply of new urban land ought to be prohibited. It is suggested that the stock urban land ought to be revitalized and the efficiency of land use improved in order to meet the demand of urban development for new urban land.

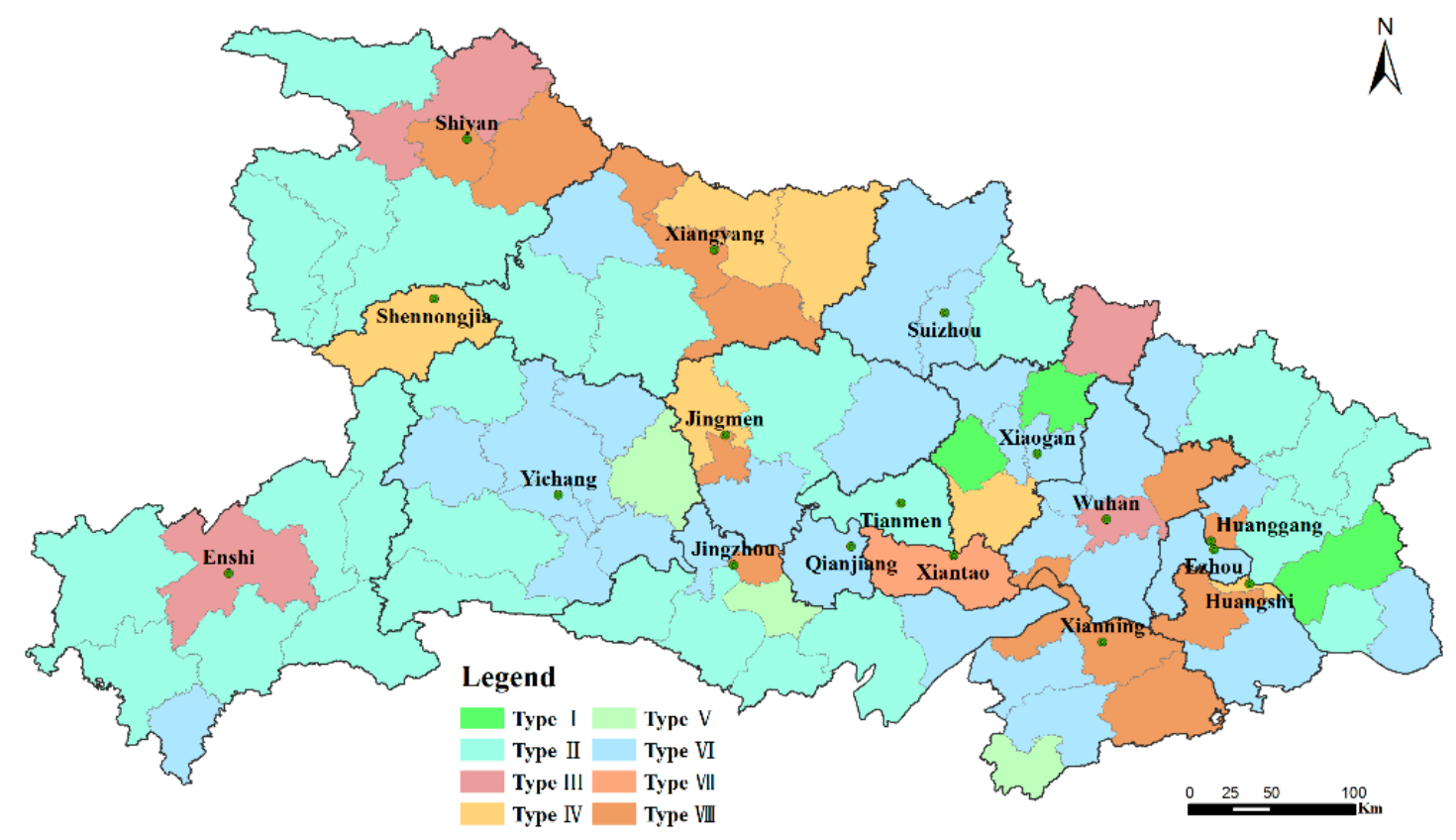

Figure 7. The pattern of the coordination relationship between RUMs and ULE. 
Table 3. Coordination relationship between RUMs and ULE. $S_{2009}$, per capita urban land area in 2009; $\mathrm{S}_{2014}$, per capita urban land area in 2014; $\mathrm{S}_{\text {stan, }}$, national standard of per capita urban land area; RUMs, rural-to-urban migrants; ULE, urban land expansion.

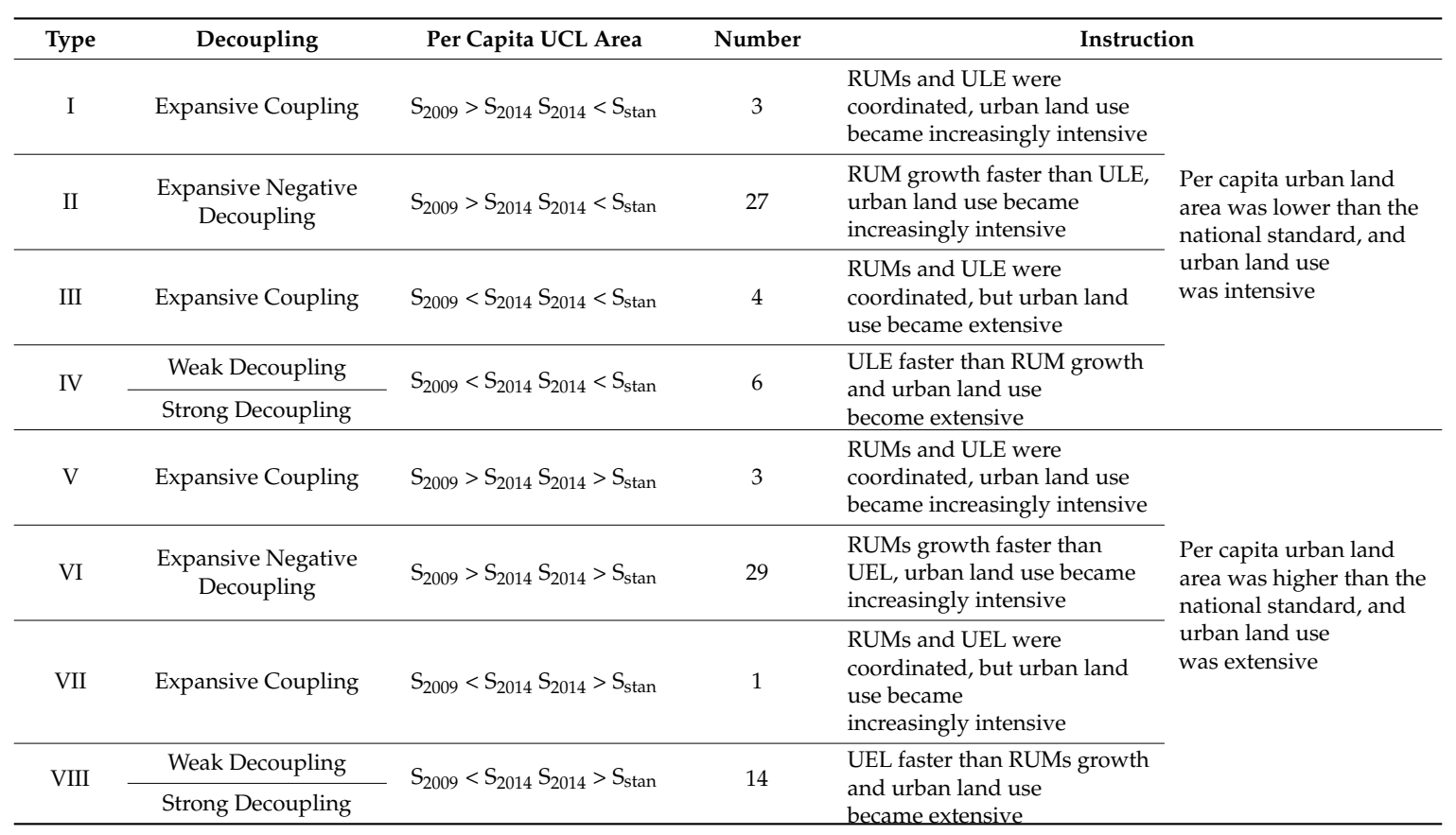

\section{Discussion}

\subsection{Inequality in Urban Development}

China has long encouraged the growth of small and medium-sized cities, and contained the growth of population in large cities [53]. The central and local governments always intended to manage city growth through planning and regulations in order to achieve equal development. However, economic development policies favor large cities. For example, large cities were granted more political power, received more investment, and enjoyed more freedom in managing local development. As a result, the economical developed large cities experienced rapid urban expansion and attracted more migration from the agricultural population [54]. Such uneven urban expansion and rural-to-urban migration intensifies the regional gaps in urban development. Our studies find that urban development in Hubei Province is highly uneven from the perspective of RUMs and ULE; the higher economic development leads to higher ULE and RUMs. For example, Wuhan city, as the most economically developed area, attracted 828927 RUMs, which accounted for more than 15\% of the RUMs of Hubei Province. The urban expansion in Wuhan city was also much higher than that of other areas.

Inequality has intensified globally and is now a fundamental issue in human society, especially since the recent global financial crisis. As a result, there is growing concern about spatial inequality in China as well. In China, the large cities have always had more political and economic power to enable them to gain development advantages, which intensifies the inequality of regional development. Rural populations prefer to migrate to large cities, in order to enjoy better public service and higher wages, while the large cities have sufficient labor to ensure sustained economic growth and rapid urban expansion. This phenomenon has widened the development gap between cities.

The development of large cities has attracted a large number of RUMs from other regions, which has greatly plundered the development opportunities of small and medium-sized cities. Meanwhile, the large cities are faced with an increasingly severe shortage of resources and energy, and a worsening ecological environment. Urban land development is a major driving force of economic development; a more balanced urban development is critical in order to lessen regional economic 
inequalities. The future economic development policies should pay more attention to the need to decentralize the land administrative power to small and medium-sized cities and equalize land use quotas across administrative units. The inequality in urban development can be gradually reduced by ensuring the urban land use in small and medium-sized cities and promoting the migration of the agricultural population to small and medium-sized cities.

\subsection{Implications for New Land Use Policy}

As a result of urbanization, many rural people have poured into cities seeking higher income, better living standards, and more job opportunities [3]. However, this migration has caused a land dilemma between urban and rural areas [55]. The increasing urban population requires more construction land in order to provide living space and to develop industries; at the same time, many houses and extensive construction land in rural areas are left unused (known as "hollowed villages"). The Chinese government has conducted an initiative land reform-the "the increasing versus decreasing balance" land use policy, which is known in Chinese as zeng jian gua gou (ZJGG)—in an attempt to get out of the dilemma in which the cities have great demand for construction land, while the villages have considerable unused and enclosed construction land [56]. This policy was developed to connect the increase in urban construction land with the decrease in rural construction land, and achieve equilibrium in the total supply of construction land [57]. The ZJGG policy promotes the integration of urban-rural development and the protection of farmland, and provides a solution to the land demand for urban development [58]. Although the ZJGG policy can help cities obtain land-use indicators, it does not pay enough attention to the problem of urban land shortage due to rapid population growth [59]. In order to solve the problem of the inconsistency of population urbanization and land urbanization in the process of urban development, a new land use policy of "population land hook", which has the Chinese name ren di gua gou (RDGG), was piloted in Henan Province with satisfactory effect and popularized nationwide in 2016. The RDGG policy is the extension of the former land policy of ZJGG, and states that the scale of ULE should be coordinated with the size of RUMs, and that the annual quota of new construction land for a city is determined by the number of attracted RUMs [60].

Restraining urban rapid growth and prioritizing the rational planning of urban land use are tasks that urban managers face in many developing countries [61]. In China, the management of the allocation of new urban land indicators was through general land planning, with a "top-down" planning mode [62]. The allocation of new urban land indicators in this planning mode is greatly affected by the local economic and administrative factors, while ignoring the human-oriented land demand. The new land use policy of RDGG aims to improve urban land use efficiency by planning control, optimizing land arrangements, and strictly implementing national PCULA standards. This policy focuses on the coordination between the RUMs and ULE. Analyzing the decoupling relationship between RUMs and ULE could serve as a useful reference for the implementation of the RDGG, and help implement targeted dynamic allocation measures of new urban land indicators according to different coordination relationships between RUMs and ULE.

\subsection{Recommendations for Future Study}

This study explored the spatial pattern of RUMs and ULE in Hubei Province from 2009 to 2014, and analyzed the decoupling relationship between RUMs and UCL. However, there are some improvements that could be made in future studies. First, the decoupling relationship between RUMs and ULE may present different patterns in different temporal dimensions; further study should add more time series data to reflect the dynamic relationship. Second, the monumental flow of RUMs in rapid urbanization also restructures the rural land pattern; the interactions between rural and urban land caused by RUMs should be explored in the further study. 


\section{Conclusions}

As a developing country, China's economic development will inevitably lead to urban expansion at the expense of cropland. At the same time, China has to maintain a sufficient amount of cropland to feed the world's largest population. Therefore, the land available for urban development is become increasingly scarce and valuable. It is of great significance for urban sustainable development to reasonably arrange the new urban land use indicators by analyzing the decoupling relationship between RUMs and ULE. This paper explored the changes of RUMs and ULE, and quantitatively analyzed the decoupling relationship between the two. The results of this study could provide valuable information for the implementation of the new land use policy (e.g., RDGG), and the sustainability of urban development. The research results are concluded as below:

(1) A large number of people migrated from rural to urban areas in Hubei Province from 2009 to 2014, and the uneven spatial distribution of RUMs was characterized by more RUMs being attracted to developed areas than to undeveloped areas; (2) The urban land area in Hubei Province increased rapidly, especially the economically developed regions, and the urban land use in Hubei Province was extensive and inefficient; (3) The decoupling types between RUMs and ULE in Hubei Province were dominated by expansive negative and weak decoupling. The western part of Hubei Province was dominated by expansive negative decoupling, whereas the decoupling types of many units in the east were weak decoupling or expansive coupling; (4) On the basis of the results of a decoupling analysis and changes in the PCULA, the coordination relationship between RUMs and ULE in Hubei Province was classified into eight categories; the relationship between RUMs and ULE in most areas were coordinated and beneficial to the intensive use of urban land, while the rest were uncoordinated.

Acknowledgments: This work was financially supported by the National Key Research and Development Program (Grant No.: 2017YFB0503505) and National Natural Science Foundation (No.: 41771432).

Author Contributions: Yaolin Liu and Enxiang Cai conceived and designed the experiment; Ying Jing and Jie Gong helped the data analysis; Ying Jing and Zhengyu Wang helped the language correction; Yaolin Liu and Enxiang Cai wrote the paper.

Conflicts of Interest: The authors declare no conflict of interest.

\section{References}

1. Deng, X.; Huang, J.; Rozelle, S.; Uchida, E. Growth, population and industrialization, and urban land expansion of China. J. Urban Econ. 2008, 63, 96-115. [CrossRef]

2. Chen, M.; Liu, W.; Tao, X. Evolution and assessment on China's urbanization 1960-2010: Under-urbanization or over-urbanization? Habitat Int. 2013, 38, 25-33. [CrossRef]

3. Zhang, K.H.; Song, S.F. Rural-urban migration and urbanization in China: Evidence from time-series and cross-section analyses. China Econ. Rev. 2003, 14, 386-400. [CrossRef]

4. Seto, K.C.; Fragkias, M.; Gueneralp, B.; Reilly, M.K. A Meta-Analysis of Global Urban Land Expansion. PLoS ONE 2011, 6, e237778. [CrossRef] [PubMed]

5. Sadorsky, P. The Effect of Urbanization and Industrialization on Energy Use in Emerging Economies: Implications for Sustainable Development. Am. J. Econ. Sociol. 2014, 73, 392-409. [CrossRef]

6. De Espindola, G.M.; Neves Da Costa Carneiro, E.L.; Facanha, A.C. Four decades of urban sprawl and population growth in Teresina, Brazil. Appl. Geogr. 2017, 79, 73-83. [CrossRef]

7. United Nations. World Population Prospects: The 2009 Revision. Available online: http://esa.un.org/ wup2009/unup/ (accessed on 14 January 2018).

8. Skog, K.L.; Steinnes, M. How do centrality, population growth and urban sprawl impact farmland conversion in Norway? Land Use Policy 2016, 59, 185-196. [CrossRef]

9. Antrop, M. Landscape change and the urbanization process in Europe. Landsc. Urban Plan. 2004, 67, 9-26. [CrossRef]

10. FAO, I. Status of the World's Soil Resources (SWSR)—Main Report; Food and Agriculture Organization of the United Nations and Intergovernment Technical Panel on Soils: Rome, Italy, 2015; p. 650.

11. Tacoli, C. Rural-urban interactions: A guide to the literature. Environ. Urban. 1998, 10, 147-166. [CrossRef] 
12. Friedmann, J. Four theses in the study of China's urbanization. Int. J. Urban Reg. Res. 2006, 30, 440-451. [CrossRef]

13. Galster, G.; Hanson, R.; Ratcliffe, M.R.; Wolman, H.; Coleman, S.; Freihage, J. Wrestling sprawl to the ground: Defining and measuring an elusive concept. Hous. Policy Debate 2001, 12, 681-717. [CrossRef]

14. Kasanko, M.; Barredo, J.I.; Lavalle, C.; Mccormick, N.; Demicheli, L.; Sagris, V.; Brezger, A. Are European cities becoming dispersed?: A comparative analysis of 15 European urban areas. Landsc. Urban Plan. 2006, 77, 111-130. [CrossRef]

15. Jiang, G.; Ma, W.; Qu, Y.; Zhang, R.; Zhou, D. How does sprawl differ across urban built-up land types in China? A spatial-temporal analysis of the Beijing metropolitan area using granted land parcel data. Cities 2016, 58, 1-9. [CrossRef]

16. Bhatta, B.; Saraswati, S.; Bandyopadhyay, D. Quantifying the degree-of-freedom, degree-of-sprawl, and degree-of-goodness of urban growth from remote sensing data. Appl. Geogr. 2010, 30, 96-111. [CrossRef]

17. Camagni, R.; Gibelli, M.C.; Rigamonti, P. Urban mobility and urban form: The social and environmental costs of different patterns of urban expansion. Ecol. Econ. 2002, 40, 199-216. [CrossRef]

18. Bai, X.; Chen, J.; Shi, P. Landscape Urbanization and Economic Growth in China: Positive Feedbacks and Sustainability Dilemmas. Environ. Sci. Technol. 2012, 46, 132-139. [CrossRef] [PubMed]

19. Lu, D.; Yao, S.; Li, G. Comprehensive analysis of the urbanization process based on China's conditions. Econ. Geogr. 2007, 20, 131-135.

20. Grimm, N.B.; Grove, J.M.; Pickett, S.; Redman, C.L. Integrated approaches to long-term studies of urban ecological systems. Bioscience 2000, 50, 571-584. [CrossRef]

21. Pal, D.; Mitra, S.K. The environmental Kuznets curve for carbon dioxide in India and China: Growth and pollution at crossroad. J. Policy Model. 2017, 39, 371-385. [CrossRef]

22. Deng, J.S.; Wang, K.; Hong, Y.; Qi, J.G. Spatio-temporal dynamics and evolution of land use change and landscape pattern in response to rapid urbanization. Landsc. Urban Plan. 2009, 92, 187-198. [CrossRef]

23. Bolca, M.; Turkyilmaz, B.; Kurucu, Y.; Altinbas, U.; Esetlili, M.T.; Gulgun, B. Determination of impact of urbanization on agricultural land and wetland land use in balcovas' delta by remote sensing and GIS technique. Environ. Monit. Assess. 2007, 131, 409-419. [CrossRef] [PubMed]

24. Shahbaz, M.; Sbia, R.; Hamdi, H.; Ozturk, I. Economic growth, electricity consumption, urbanization and environmental degradation relationship in United Arab Emirates. Ecol. Indic. 2014, 45, 622-631. [CrossRef]

25. Sarvestani, M.S.; Ibrahim, A.L.; Kanaroglou, P. Three decades of urban growth in the city of Shiraz, Iran: A remote sensing and geographic information systems application. Cities 2011, 28, 320-329. [CrossRef]

26. Fang, C. China's Urbanization Process and Resources Environment Protection Report; Science Press: Beijing, China, 2009.

27. Liu, Y.; Fang, F.; Li, Y. Key issues of land use in China and implications for policy making. Land Use Policy 2014, 40, 6-12. [CrossRef]

28. National Bureau of Statistics of China. China Statistical Yearbook 2015; China Statistical Press: Beijing, China, 2015.

29. Chan, K.W.; Zhang, L. The "hukou" system and rural-urban migration in China: Processes and changes. China Q. 1999, 160, 818-855. [CrossRef]

30. Cai, H.; Wang, J. Factors influencing the migration intentions of rural workers in the Pearl River Delta. Soc. Sci. China 2008, 29, 157-171. [CrossRef]

31. Song, Y.; Sun, W. Health consequences of rural-to-urban migration: Evidence from panel data in China. Health Econ. 2016, 25, 1252-1267. [CrossRef] [PubMed]

32. Murphy, R.; Zhou, M.; Tao, R. Parents' Migration and Children's Subjective Well-being and Health: Evidence from Rural China. Popul. Space Place 2016, 22, 766-780. [CrossRef]

33. Ao, X.; Jiang, D.; Zhao, Z. The impact of rural-urban migration on the health of the left-behind parents. China Econ. Rev. 2016, 37, 126-139. [CrossRef]

34. Zhu, N. The impacts of income gaps on migration decisions in China. China Econ. Rev. 2002, 13, $213-230$. [CrossRef]

35. Su, Y.; Tesfazion, P.; Zhao, Z. Where are migrants from? Inter- vs. intra-provincial rural-urban migration in China. Available online: https:/ / doi.org/10.1016/j.chieco.2017.09.004 (accessed on 29 January 2018).

36. Wang, G.; Huang, Z. The growth composition of urban population in china and its contribution to urbanisation: 1991-2010. Chin. J. Popul. Sci. 2014, 2, 2-16. 
37. Chan, K.W. Urbanization and rural-urban migration in China since 1982: A new base-line. Mod. China 1994, 20, 243-281. [CrossRef]

38. Zhu, Y.; Lin, L. Studies on the Temporal Processes of Migration and Their Spatial Effects in China: Progress and Prospect. Sci. Geogr. Sin. 2016, 6, 820-828.

39. Carter, A.P. The Economics of Technological Change. Sci. Am. 1966, 214, 25-31. [CrossRef]

40. Organization for Economic Co-operation and Development. Indicators to Measure Decoupling of Environmental Pressure and Economic Growth; Organization for Economic Co-operation and Development: Paris, France, 2002.

41. Tapio, P. Towards a theory of decoupling: Degrees of decoupling in the EU and the case of road traffic in Finland between 1970 and 2001. Transp. Policy 2005, 12, 137-151. [CrossRef]

42. Romano, B.; Zullo, F. Land urbanization in Central Italy: 50 years of evolution. J. Land Use Sci. 2014, 9, 143-164. [CrossRef]

43. Enevoldsen, M.K.; Ryelund, A.V.; Andersen, M.S. Decoupling of industrial energy consumption and $\mathrm{CO}_{2}$-emissions in energy-intensive industries in Scandinavia. Energy Build. 2007, 29, 665-692. [CrossRef]

44. Wang, C.; Liu, Y.; Kong, X.; Li, J. Spatiotemporal Decoupling between Population and Construction Land in Urban and Rural Hubei Province. Sustainability 2017, 1258. [CrossRef]

45. Statistics Bureau of Hubei Province. Hubei Statistical Yearbook 2015; China Statistics Press: Wuhan, China, 2016.

46. Northam, R.M. Urban Geography; John Wiley \& Sons: New York, NY, USA, 1975.

47. Liu, Y.; Luo, T.; Liu, Z.; Kong, X.; Li, J.; Tan, R. A comparative analysis of urban and rural construction land use change and driving forces: Implications for urban-rural coordination development in Wuhan, Central China. Habitat Int. 2015, 47, 113-125. [CrossRef]

48. Ministry Of Land and Resource of China. Current Land Use Condition Classification. In GB/T21010-2007; Ministry Of Land and Resource of China: Beijing, China, 2007.

49. Statistics Bureau of Hubei Province. Hubei Statistical Yearbook 2010; China Statistics Press: Wuhan, China, 2011.

50. Makido, Y.; Dhakal, S.; Yamagata, Y. Relationship between urban form and $\mathrm{CO}_{2}$ emissions: Evidence from fifty Japanese cities. Urban Clim. 2012, 2, 55-67. [CrossRef]

51. Zeng, C.; Yang, L.; Dong, J. Management of urban land expansion in China through intensity assessment: A big data perspective. J. Clean. Prod. 2017, 153, 637-647. [CrossRef]

52. Ministry Of Housing and Urban-Rural Development. Code for classification of urban construction land. In GB50137-2011; Ministry Of Housing and Urban-Rural Development: Beijing, China, 2010.

53. Henderson, J.V.; Logan, J.R.; Choi, S. Growth of China's Medium-Size Cities. Brook.-Whart. Pap. Urban Aff. 2005, 2002, 263-303. [CrossRef]

54. Wei, Y.D.; Li, H.; Yue, W. Urban land expansion and regional inequality in transitional China. Landsc. Urban Plan. 2017, 163, 17-31. [CrossRef]

55. Chen, R.; Ye, C.; Cai, Y.; Xing, X.; Chen, Q. The impact of rural out-migration on land use transition in China: Past, present and trend. Land Use Policy 2014, 40, 101-110. [CrossRef]

56. Long, H.; Li, Y.; Liu, Y.; Woods, M.; Zou, J. Accelerated restructuring in rural China fueled by 'increasing vs. decreasing balance' land-use policy for dealing with hollowed villages. Land Use Policy 2012, 29, 11-22. [CrossRef]

57. Tian, L.; Guo, X.; Yin, W. From urban sprawl to land consolidation in suburban Shanghai under the backdrop of increasing versus decreasing balance policy: A perspective of property rights transfer. Urban Stud. 2017, 54, 878-896. [CrossRef]

58. Long, H.; Liu, Y.; Wu, X.; Dong, G. Spatio-temporal dynamic patterns of farmland and rural settlements in Su-Xi-Chang region: Implications for building a new countryside in coastal China. Land Use Policy 2009, 26, 322-333. [CrossRef]

59. Li, M.Q.; Tian, Y.; Niu, H.P. Analysis of the similarities and differences between the connecting of labor and arable land and the connecting of the increase in urban construction land and the decrease of rural construction land and implementation principles. Res. Agric. Mod. 2015, 36, 105-110.

60. Ministry of Land and Resource of China. Opinions on the Establishment of a Mechanism for Linking the Scale of Urban Construction Land Increase and the Number of Rural-to-Urban Migrants; Ministry of Land and Resource of China: Beijing, China, 2016. Available online: http:/ /www.mlr.gov.cn/zwgk/zytz/201610/t20161010_ 1418921.htm (accessed on 18 September 2017). 
61. Awuah, K.G.B.; Hammond, F.N.; Lamond, J.E.; Booth, C. Benefits of urban land use planning in Ghana. Geoforum 2014, 51, 37-46. [CrossRef]

62. Guo, J.; Bao, Q.; Ming-Hao, O.U. Study on Incremental Construction Land Quotas Allocation in China based on Resource Endowments and Economic Development Regional Differences. China Land Sci. 2016, 30, 71-78.

(C) 2018 by the authors. Licensee MDPI, Basel, Switzerland. This article is an open access article distributed under the terms and conditions of the Creative Commons Attribution (CC BY) license (http:/ / creativecommons.org/licenses/by/4.0/). 